\title{
Looking Back, Looking Ahead: An Interview with Professor ZhaoHong Han
}

\author{
Peter Kim, Wai Man Adrienne Lew, and Haimei Sun \\ Teachers College, Columbia University
}

\section{INTRODUCTION}

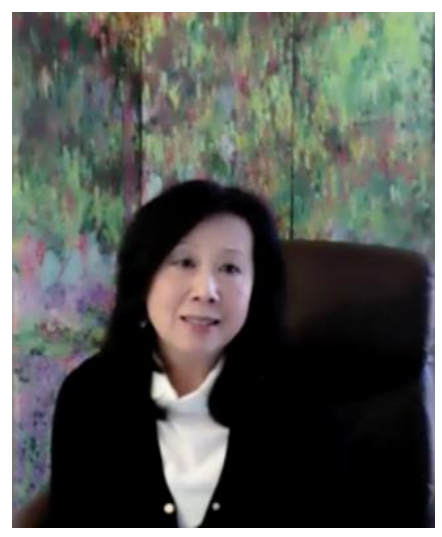

On April 8, 2021, we had the great pleasure of speaking over Zoom with Professor ZhaoHong Han, the founding editor of SALT, which was originally called Working Papers in TESOL and Applied Linguistics. In celebration of the journal's $20^{\text {th }}$ anniversary, we discussed the motivation and vision behind establishing a web journal, future directions, essential qualities of an outstanding original research article, and advice for early career scholars and graduate students who are starting out to get their work published in journals.

$\underline{\text { Dr. Han is Professor of Applied Linguistics and Director of the Center for }}$ International Foreign Language Teacher Education (CIFLTE) at Teachers College, Columbia University. She also directs the new TC-Tunisia Foreign Language Teacher Education project, funded by the U.S. State Department. Dr. Han's scholarly interests are broadly in second language learnability, second language teachability, and their interface. Her work on fossilization, $\underline{\text { crosslinguistic }}$ $\underline{\text { influence, }}$ corrective feedback, second language thinking for speaking, second language reading and vocabulary

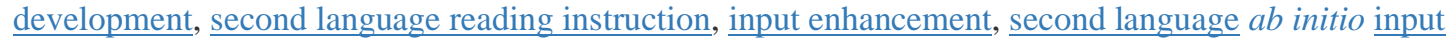
processing, task-based language learning, and foreign language teacher education, among other topics, has appeared in a variety of journals and books. She is the recipient of the 2003 International TESOL Heinle and Heinle Distinguished Research Award and a repeated recipient of the Teachers College, Columbia University Outstanding Teacher Award.

\section{PATH TO SECOND LANGUAGE ACQUISITION RESEARCH}

Han: I have a passion for foreign languages, and I think I have a little bit of a talent for that. I came from a family of teachers, so I grew up wanting to be a teacher, but it just happened that I became a foreign language teacher and from there, I went on to graduate studies that would prepare me for becoming both a practitioner and a researcher. I always see teaching as a noble profession. So being in this field has to do not only with the fact that I have wanted to be a teacher, but also that I see the meaningfulness of this career and have the desire to help other people, knowing how difficult it is for individuals to learn a foreign language, especially if they started out late in life. Being an instructor of foreign languages, I've had experience teaching multiple languages. And, being a researcher in the field, I wanted to know more about how that process of learning happens and how instructors can harness that understanding toward being more effective in the classroom, and I wanted to be more helpful to the field and to other practitioners in the field. I've discovered over the years that I had a passion for research. The more I engaged in it, the greater passion I developed for doing research. I love intellectual challenge. If life were not filled with challenges, I would have found it boring. I constantly feel 
the urge to create and produce work. I very much enjoy the exploratory process, including the solitude of being alone and being fully engaged in thinking. I care about questions that we have and the questions the field faces, both big questions and small questions. As a matter of fact, in my advising, I've always been encouraging my doctoral students to explore both 'the forest' and 'the trees', not just to do one without the other. Students tend to get bogged down with 'isolated trees.' I've been encouraging them to broaden their scope of reading, their horizon, their understanding of the field, because there is an intimate connection between trees and the forest.

\section{MOTIVATION BEHIND THE WEB JOURNAL}

Han: I've always loved technology. That's another facet of me if you will. I feel that I have some natural instinct for it. As a PhD student 30 years ago, of the many jobs I worked, I served as an assistant for a technology course teaching people how to log into a computer and how to navigate Microsoft Word. I even learned HTML, the web language that was popular then. My husband often jokes with me, saying that I would make a good member of the TC help desk team.

As a young faculty member joining the TESOL and Applied Linguistics Program in the late 1990s, I wanted to do something creative for the Program. I wanted to create synergy among doctoral students across the three tracks and to help them engage with real-world experience of the editorial process. I wanted to create an outlet for them to publish their work-in-progress. Essentially, I wanted a journal by our doctoral students and for our doctoral students. At that time, I was very much inspired by a journal published by the University of Hawaii, called Working Papers in ESL Studies. That journal evolved over time into a very influential outlet. Authors such as Craig Chaudron, Mike Long, Graham Crookes, and Robert Bley-Vroman all published in the Working Papers put out by the University of Hawai'i at Manoa. And in fact, one of the first papers on TBLT appeared in that journal, which has gotten cited by so many people. That paper was authored by Crookes and Long and has remained a seminal paper for students to read if they want to understand TBLT. I wanted our students at Teachers College to have an authentic editorial experience and I thought that the experience would, in turn, facilitate their own work and their own dissertations. I wanted a process for the doctoral students but also a product, both for members of the editorial board and those students who contributed to the web journal by either having their work published or considered for publication. In addition, I wanted the doctoral students in our program to have an opportunity to build authentic credentials for their future career, something that they could put in their resume, that they could show to their future employers at the time when they began their job hunting. And, indeed, numerous doctoral students in our program who had web journal publications in their resumes were able to find employment in higher education because those publications counted. I also wanted the web journal to be a place of incubation, which is why I decided to go with the title of "working papers," where our students could experiment with their ongoing ideas for their dissertations or for some other academic projects. So, yeah, that's just about as much as I can recall at this point.

\section{QUALITIES OF OUTSTANDING RESEARCH}

Han: From my perspective, I think it is important to conduct authentic, original, and useful research that engages with a real question based on a good understanding of what has or has not 
been done in the field, addressing a real issue. Authentic research cannot come out of individuals whose motivation to publish is just because they want to have some publications. In other words, the heart of the researcher needs to be in the right place. The researcher needs to have a desire to help advance the field of study and the study design needs to be thoughtful with a lot of reasoning, not just a shallow treatment of the existing literature. The need to engage with the issue is real, both at the theoretical and the methodological level, and there's a need to follow or to adopt or to create principled approaches to doing research in our field. And that requires a juxtaposition of theoretical reasoning with existing empirical studies, because without principled approaches to doing research, there's not going to be solid replication research. What we're seeing right now with many journals is that they publish a lot of studies, one study after another, but when we ask ourselves, are we advancing our understanding? Probably not much. So, I see a real need to adopt a principled approach to doing research with a lot of reasoning, both at the theoretical and the empirical level. Real research, as a result, should not be narrow, it should not be simplistic, and it should not be reductionist. Take the pretest-posttest design as an example which has been a very popular approach to doing interventional studies. But that kind of design essentially implements a reductionist approach to understanding learning because there are so many important variables that have not been considered, or have been ignored. "Time" for one is ignored. "Time" is a variable. As time changes, the conditions for learning, the conditions for development, change. The conditions that are present at the time of pretesting are not necessarily the conditions that are present at the time of post-testing. So, even with a pretest and a posttest, which seemingly creates a longitudinal perspective, the essence of time - how time contributes to the development - has not actually been seriously considered. The whole process of learning has been simplified and reduced. Learning is far more complex than that. So, absolutely, SLA studies from my perspective must take time and space into account and the individual nature of development. Individuals learn very differently. I've had an opportunity to discuss some of these concerns at the 2021 AAAL colloquium on Complex Dynamic Systems Theory, serving as a discussant. In a nutshell, I've been advocating systems thinking. It's so necessary or else our understanding will be skewed, biased, and fragmentary. And this is not even to mention that as an SLA researcher, we have an enormous social responsibility on our shoulders. If we adopt a reductionist approach to research and produce findings that are actually biased or accidental, and if we expect practitioners in the field to read about these findings and to then replicate them in the classroom, it's just hard to imagine the outcome and consequence. Looking from all directions, there's such a need for us to be broader rather than narrower, for us to conceptualize the learning difficulty or challenges as complex phenomena, and to take time and space and what the individual learner brings into this system into account when designing and conducting empirical research.

I think there's a need for authentic and organic research to consider building triangulation into the process, looking at learning from multiple perspectives within an ecosystem that includes time, space, and the learner. I would also say that it is necessary for us to recognize as well that SLA research, as the past decades have already shown, is not monolithic, so I'm all for carving out domains like basic SLA, instructed SLA and applied SLA so that these domains can engage with specific sets of questions. The questions that confront the basic SLA domain may not be immediately applicable to applied SLA research or research done in real settings like in schools. These are just some of the things that have come to mind regarding doing useful and usable research--organic and authentic research. 


\section{FUTURE ADDITIONS AND WAYS TO INCREASE THE JOURNAL'S IMPACT ON THE FIELD}

Han: What we need is our own journal that uniquely fulfills our own needs, while at the same time contributing to the field filling a gap in publication outlets. Also, considering that all these years it has remained a challenge to solicit submissions: In spite of the calls you put out there on various listservs, the challenge has remained. And here's another reality: the increasing number of new outlets. I can't tell you how many invitations I get on a daily basis, asking me to submit a manuscript to a new journal, so this has been ongoing. We need to think more about our own niche, create it and build it and not to enter a competition with other journals. That's a non-starter for me. So, one concrete idea that I have is to change the format of the journal a little bit by having a main article, followed by 8 to 10 commentaries on that article, analyzing that article. I think this can be very helpful, not only to the author of the main article, to the contributors, to the commenters, but also to our own students who are in the process of working on their own dissertations and to the graduate students in the real world out there. So that way you're not only free from feeling compelled to beg people to contribute to the journal; you're also creating something potentially very useful. The commenters can be our own people, but they can also be graduate students from elsewhere. This is more like a process-oriented way of creating our own niche. It could be a great thing for graduate students worldwide to see something being broken down, being analyzed by different people from different perspectives, and to get critical feedback. Getting critical feedback nowadays is not easy. A lot of people are unwilling to actually do that, but our journal can create a venue for that kind of real academic discussion to take place. Like I said, the commenters don't have to be our own doctoral students, though they can be, and even master's students can be invited to serve as commenters. So this would broaden the scope of participation. Think about inviting graduate students from other institutions to serve as commenters. This would be an opportunity for them to get something published, and it would just make the discussion so interesting and it would also enable the building of a much wider network. The whole idea is to implement diverse perspectives, to critically dissect a piece of research, and to turn this into a source of very useful, interesting feedback for the contributors.

The web journal, as I said earlier, can be a place of incubation. The students can use the opportunity to incubate ideas, to field test their ideas and see what people might have to say about those ideas. I would like to suggest keeping the nature of this journal being about work-inprogress. There's one other advantage to it, and that is, originally when I founded the journal, the idea was also that papers published in this journal could still be submitted to another journal.

So, again, there might be a need to connect with other graduate programs around the country or even internationally, but this is a process and it takes time. And the format is something that I've just mentioned: a main article and dissecting that article with analytic commentaries. In order to do that, it's important for the Editorial Board to expand its own horizon so that you're sensitive to emerging topics and themes, but of course, the editor and the Editorial Board can also consult with other people, including their advisors, faculty members and so forth.

\section{ADVICE FOR DOCTORAL STUDENTS}


Han: First of all, doctoral students ought to have a passion for learning. They should enjoy the process and they need to have the right motivation as well for embarking on doctoral studies. Motivation is really key to success in this process. If you allow me to invoke Gardner's (1985) definition of motivation: motivation is not one thing; it's a combination of factors: it's effort plus desire to achieve the goal of learning, plus favorable attitudes toward learning the language. For this context, I can reformulate it and say that the motivation for doctoral students is effort. Without effort you're not going to get anywhere; plus, a desire to achieve the goal of completing a doctoral dissertation; plus, a favorable attitude toward engaging and reengaging with the developmental process involving critical feedback. That kind of motivation is what's needed. The willingness to engage is also important and the ability to engage, including engaging with critical feedback and recognizing that development is a complex nonlinear process involving progression and regression and even digression. That recognition is key to succeeding in this process. It's not an easy process. It's a difficult and challenging process. The process requires perseverance, tenacity and stamina. Any underestimation of the process, of the amount of effort, or of the need and the ability to engage with critical feedback is not going to bode well for the outcome.

\section{ADVICE FOR EARLY CAREER SCHOLARS AND GRADUATE STUDENTS IN APPLIED LINGUISTICS RESEARCH}

Han: There's no need to wait until you're a mature researcher to begin to publish your work. And I think our students should feel free to give it a shot. Our web journal is a unique outlet to facilitate the learning process for developing researchers, that is, the students who are in the graduate programs, including doctoral students as well as master's students. And I would say to our students that there is really nothing to lose, even if the submission is rejected, because there's one thing guaranteed: the submission would receive feedback. I think early career or developing researchers should feel free to submit work for consideration for publication in the web journal. It can be a great learning process.

Let's keep this in mind: rejections are the staple of academic work. You know why you're getting rejections? Because you're trying to break out; you're trying to do something new. But there are so many conditions that come together, that interact and decide whether you will be successful or not successful. There are many subjective elements and there are many objective elements interacting. Your work can be rejected, only because somebody serving as a reviewer or the editor doesn't like the work you do, and that's part of the reality. My advice to people who have been intimidated or discouraged by rejections is: Never be intimidated because if you do, you will never stand a chance to get on to another level. The best you can do is keep trying and learn from the feedback.

The newer the thing you do, the higher the chance of being rejected. Let's face it. It's always challenging to push something new out there because the general psychology is that people like seeing what they're used to. If it's something unconventional, and if it's something new, then people who don't understand it tend to err on the side of rejecting it. Ironically, this is the 'best' part of what people experience when they try to be innovative and push for new ways of thinking. But the world presents options. If one outlet is not successful, try another outlet. That's the beauty of the world. The world doesn't present you with one option; there are so many 
options. In our field, there is the tradition of people talking about issues and yet without seriously engaging with them, and, to some extent, journals have helped perpetuate the status quo. So, speaking of that, I think our web journal can push the envelope, doing something interesting and new.

Thank you very much for the opportunity to speak with you on this momentous occasion. And congratulations on the $20^{\text {th }}$ anniversary. We're very fortunate to have a very dedicated team of advising faculty and editorial board members. Under their strong stewardship, there is no doubt that the journal will see monumental development in the years to come.

\section{REFERENCES}

Gardner, R. C. (1985). Social psychology and second language learning: The role of attitudes and motivation. Edward Arnold.

Peter Kim is an Ed.D. candidate in Applied Linguistics at Teachers College, Columbia University, specializing in second language acquisition. His research interests are language motivation and language aptitude in SLA.

Wai Man Adrienne Lew is an Ed.D. candidate in Applied Linguistics at Teachers College, Columbia University, specializing in second language acquisition. Her research interests include L2 input, interlanguage fossilization, and the L2 acquisition of tense and aspect.

Haimei Sun is an Ed.D. candidate in Applied Linguistics at Teachers College, Columbia University, specializing in second language acquisition. Her research interests include task-based language teaching and learning, second language reading, eye-tracking, and automatic text processing. She is currently the academic coordinator of the Center for International Foreign Language Teacher Education (CIFLTE) at Teachers College. 